\title{
Survey and Analysis of University Clustering
}

\author{
Srinatha Karur ${ }^{1}$, Prof.M.V.RamanaMurthy ${ }^{2}$ \\ ${ }^{1}$ Oracle DBA \& Technical Support, Ibra College Of Technology \\ ${ }^{2}$ Professor \& Director, School of Computer Science, Osmania University, \\ ${ }^{1}$ karur_srieyahoo.co.in , ${ }^{2}$ mv_rmerediffmail.com
}

\begin{abstract}
:
This paper gives on Clustering of Universities in the world with respect to their country policies OR local polices OR continent level polices with sub aims. So clustering method can generally apply when objective is specifically mentioned. For general objectives clusters are available in the form of logical or physical groups without networks. In this paper we emphasis on only University Clusters directly or University Clusters with some other clusters. Data miming methods are used for useful for Sampling Analysis and Clustering of Universities and Colleges with respect to local clusters [1] pp 1.
\end{abstract}

\section{KEYWORDS:}

University Clustering, Policies, Survey, Data Mining methods, UGC.

\section{INTRODUCTION}

This document describes survey on University clustering, as global and efforts are concentrated for new model of University clusters. In India this cluster technology is at very initial stage and we do not have any perfect Government policies and implementation plans. But University Grants Commission has announced its Cluster college system for next five years plan [22]. Basically India is agriculture oriented country and developing country [26]. So extreme efforts are necessary to define the Education cluster policy for entire nation [25], pp 1-2. Due to lot of heterogeneous conditions of country it is necessary to have different policies for different regions [26]. This research work addresses mainly on survey on different Universities in the world for clustering policies and their implementations in different fields. Samples are considered from University level, Continent level, and Institute level from all parts of the world. Data Mining methods are useful to solve a problem as either supervised method or Unsupervised method as per given policy or objective of problem. Finally UGC policy is treated as tentative policy of Ministry of Human Resources, Government of India.

\section{OBJECTIVE}

Our research objective is estimate the type of clusters for Indian Universities using different developed countries cluster policies and different case studies across the world. After getting the clusters the data should be Visualize with supported tools. Supervised methods are applied wherever necessary condition takes place.

DOI : $10.5121 /$ ijaia.2013.4412 
International Journal of Artificial Intelligence \& Applications (IJAIA), Vol. 4, No. 4, July 2013

\section{RELATED WORK}

\subsection{University level Clustering}

The Excellence Initiative of the German Federal Ministry of Education and Research and the German Research Foundation aims to promote cutting-edge research and to create outstanding conditions for young scientists at universities, to deepen cooperation between disciplines and institutions, to strengthen international cooperation of research, and to enhance the international federal government and the German states. More than 30 universities in total received funding. It includes three clusters [2].

William Peterson University, New Jersy,USA Cluster Program has been offering courses to freshmen for over 15 years and has received an enthusiastic response from students and faculty alike. Students find it is easier to make friends in smaller classes, to relate to their teachers, and to be interested in the courses which are more connected with each other. In all semesters subject wise clusters and Research clusters are available. Semester implementation is on the basis of 2 clusters and Research Departments have 5 clusters [4].

The National University of Singapore (NUS) Faculty of Arts and Social Sciences (FASS) set up multidisciplinary Research Clusters in 2006. Since then the cluster group has grown to seven clusters and continues to foster academic excellence by promoting high-impact research in innovative areas of relevance to Singapore and the Asian region. The Science, Technology, and Society (STS) Research Cluster studies the inter-relationships between the domains, especially in the context of Asia. As the newest cluster in ARI (August, 2009) is the smallest, but work closely with the existing, larger STS Research Cluster in the Faculty of Arts and Social Sciences (FASS) [5]. Intra cluster, inter cluster, Bi-cluster, and multiple clusters are available as per policies [6] [7] [8].PC-Clusters are available on the basis of personal computers which logically tends to Technical clusters [7] [9].

The Exeter University, United Kingdom has Institute of Arabic and Islam studies as affiliated body. It has 3 clusters. They are Islamic Studies, History and Social Sciences, and Languages. Using Literature the links which have developed between Arabic literature and European literature since the late 19th century. Within the University,consistant internal clusters are available [27].

The San Francisco University, USA has number of clusters which are purely internal clusters. Mainly they are Research, Science and IT, Literature, Engineering, and others [14].

The Sultan Quaboos University has its own affiliated hospital and Technical clusters are available for Hospital patient system. Linux clusters are available as physical clusters. With Fujitsu's solution, instead of spending a whole day dealing with a single request, now it can be closed within few minutes, all from one central console [15].

Dubai International Academic City was launched in April, 2007 in response to the tremendous growth witnessed by Universities in the Dubai Knowledge Village campus [16]. This organization has 5 clusters [29]. The five clusters are Industry clusters, human resource development clusters, region's leading centers of excellence for learning and human capital, DOZ clusters to set up a regional hub to expand operations in the Middle-East and African markets, and other clusters. (Other clusters such as DIC, DMC, DKV)

King Abdullah University of Science and Technology, Saudi Arabia consists of number of internal 
clusters [17].Mainly it consists of Research park and Innovation cluster, National Industry clusters, Introductory cluster, Technology cluster, Technical cluster etc.

University Innovative clusters closing the gap between University and Society in East Africa (Uganda and Tanzania Case studies). Innovative Cluster Initiatives aim to bring up internal entrepreneurship in individual firms in close collaboration with similar firms in the same location and with academic researchers and government officials in a Triple Helix process. These two different real time applications in different countries can achieved their targets with, Research and Economic clusters. Research scholars worked closely along with all others in other cluster improved the quality of work [18].

University of Dalhousie, Canada consists of lot of internal clusters. Mainly they are Academic and themed clusters, Medical sciences clusters for find out the injuries as clusters [31], Research and Center clusters, Pure Academic clusters,PC clusters, Environment clusters, Local and Regional clusters, High Power Computer clusters, Student services clusters [32], etc. University has receiving \$140 Million for Research clustering.

University Of Massey, New Zealand consists of 4 important clusters. They are Community, Loci, Academic and Research clusters. The Research Support Services at Massey University consists of four clusters that provide policy and operational support to all research related activities within the institution. These functions range from providing support to doctoral and research students, assisting in the development of funding proposals and associated contracting, budgeting advice and project management, providing training and development opportunities for staff and students at all stages of their research career and policy development and implementation to support the Research Strategy 2012 - 2014 [33] [34] [35].

The 1st New Zealand e-research Symposium will be held in the Owen G Glenn Building, at The University of Auckland, on 26-27th of October, 2010 [37]. In this Symposium they discussed on Computational clusters, deploy the Institititional clusters, and Computational queuing clusters [36].They used language $\mathrm{R}$ as Grid cluster at Application level [38]. It is possible for a .NET developer to write and compile console applications on Windows that can be executed on suitably prepared Rocks HPC clusters [39].

Clusters and Competitiveness of Automotive Companies in Slovakia (Case Study) mainly have 3 big car companies and they convert into Bi-cluster for high profits and quality. They achieved Academic cluster as internal cluster. This annual conference is joint venture of Australia and New Zealand Academy of Management. In terms of 4 Hypothesis they implemented the cluster policy [40].

The University of Iowa(UI), USA has lot of clusters [47].Mainly it has 5 objectives and five years strategic plan in the cluster hire initiative.. The 2009 Water Sustainability cluster emanated from President Mason's call for a strengthened emphasis on sustainability at UI. The 2010 clusters in Digital Public Humanities and Aging Mind and Brain have their origins in the UI Strategic Task Force reports of 2009. The 2011 call for cluster proposals was open, encouraging faculty to submit their ideas for successful clusters [48], pp2, pp5. They submitted report with 11 recommendations. All these recommendations are emphasis on Finance, Admin and Faculty clusters with logical flow [49], pp 3. 
International Journal of Artificial Intelligence \& Applications (IJAIA), Vol. 4, No. 4, July 2013

An Emerging Research cluster: India. Consists of 4 types of clusters. They are Industry clusters, Activity clusters, India and China activity cluster and Research cluster. Flow between University and Industry clusters is logical and physical also. Global strategy, long term commitment, staffing, and lack of exact knowledge between local and global needs etc. are the main issues in the Research cluster [50], pp 7-8.

Presidency University, Calcutta, India has been declared the first" Cluster Innovation Centre" (CIC) in Eastern India by the Govt. of India. Cluster Innovation Centers would promote innovation in and around the university system by" The National Innovation Council". CICs are expected to function as independent bodies inside the university and facilitate collaborations to create new knowledge, products, and processes. Academic and Research clusters are mainly focused in CIC [41] [42].

Delhi University, Delhi, India has been declared as Cluster Innovation Center (CIC) in North India by the Govt. of India. It has University level Governance and several projects are in progressive way. Along with Research Innovations, other Real time application projects are going on (Car Queuing system, Mathematics and Music relation). College Innovation Projects, Village Cluster Project, Student Internship \& Projects, Engineering Kitchen etc. are also part of Delhi University CIC. All projects are funded by University itself [43].

\subsection{Country Level Clustering}

ATTRACT, funded in 2009 under the EU flagship programme "Lifelong Learning", is a follow up initiative of a Swedish national project which had the main objective of investigating the attractiveness of young and dynamic students. Finland, Ireland, Italy, Portugal, Sweden, Belgium, Germany are the participated countries. The project's aim is construct the clusters on different modes like Gender, Science, Arts, Engineering, and country wise also. All participated countries have general information of member countries. In this we have inter, intra and bi-clusters are available. Ministry of Higher Education and Ministry of Commerce and Industries have joint venture on this project. [44].

Enhancing the Creative, Digital and Information Technology Industries (CDIT) in Brighton- an Arts and Humanities Research Council (AHRC) Project mainly deals about "Role of Universities on enhances the clusters". Mainly this project focused on not only on its title and also on Economics, Networks, Relation between University and Industry, Digital clusters, and knowledge exchange. This project is sponsored by University of Brighton USA [45].

Australian Research Council (ARC), Govt. of Australia, consists of bi-clusters between ARC, Excellency in Research for Australia (ERA), and Research Evaluation Committee (REC).Research Evaluation Committee (REC) helps ERA on the basis of Citation Analysis, Ranked outlets, Income Research, Bibliometrics and Scientometrics (Quality vs. Quantity).They have Physics, Chemistry, Earth-Sciences as one cluster and Humanities and Creative Arts as another cluster [46], pp 20.

Arabic Cluster: A bridge between East and West consists of 5 members namely Egypt, Morocoo,Turkey,Kuwait, and Qatar are located in the Middle East. The main aim of cluster is to determine the Economic development in this area when compare to Global cluster. It also deals about detailed nature of all cluster members and have awareness of border members. Before the 
independence all these countries are under British Empire. This is an initial sample for supervised learning in Middle East [28].

Ranking and Clustering Australian University, Research Performance, 1998-2002: This paper deals about the clusters, ranks and the research performance of thirty-six Australian universities over the period of 1998-2002. Research performance is measured according to audited numbers of $\mathrm{PhD}$ completions, publications and grants (in accordance with rules established by the Department of Education, Science and Training) and analysed in both total and per academic staff terms.Hierachical Clustering is used on all 36 Sampling Universities from Australia Country or Continent. Supervised Learning is used for Statistical Analysis [53], pp 8-9. Dendogram is not shown by the original authors [53]. In some applications proximity data is available then hierarchical approach may be better [53],pp 1-22, [54],pp 198.ANOVA results are also not shown by original author.ANOVA analysis and Outliers are implemented with TANAGRA 1.4 version software. There are totally 168 rules are generated with Association Rule Editor from Tanagra Tool. Only zero examples are idle.

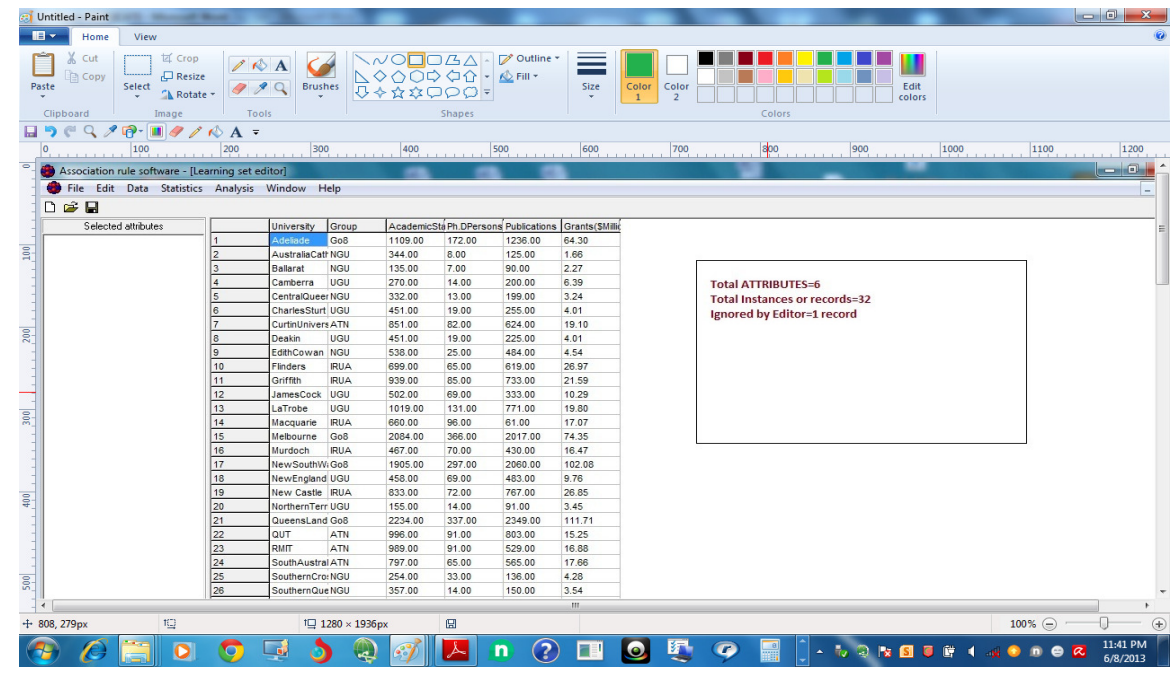

Figure 3.2a: Association Rule Editor(TANAGRA)

ANOVA analysis between Input and Target (Ph.D and Group) has same Fishery statistics with respect to P-Value OR Input OR Output.This screen shot is with respect to P-Value.Remaing two combinations(Input and Output) not shown due to same result. 
International Journal of Artificial Intelligence \& Applications (IJAIA), Vol. 4, No. 4, July 2013

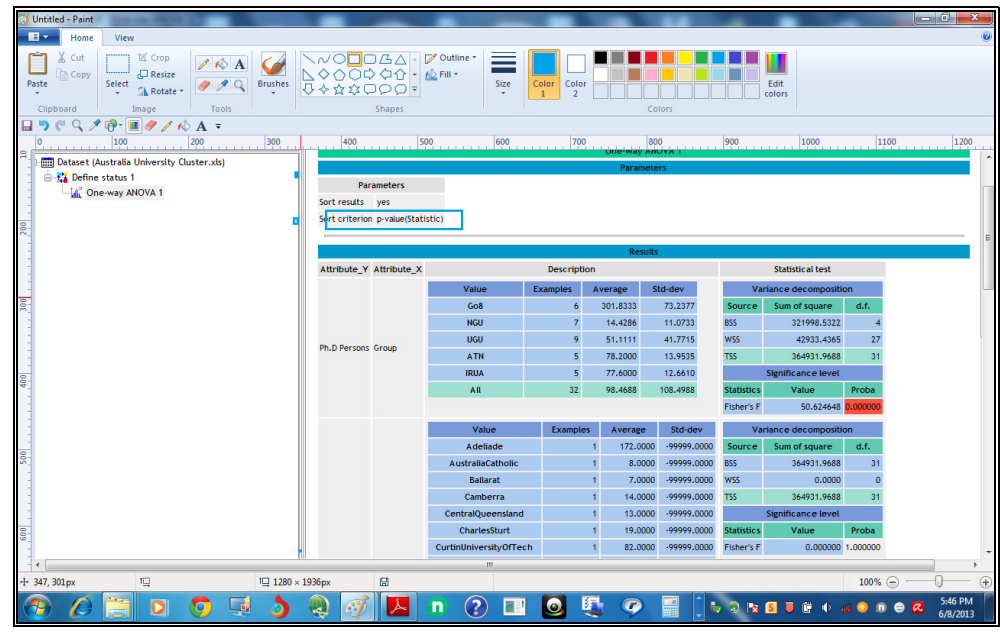

Figure 3.2b: ANOVA for Input and Target

Outlier detection for above 6 attributes and 32 instances are 5.It is not possible to remove the errors completely or partially.If we use Sigma Value method we can not find the outliers.For outer or inner fense we can find errors.For Inner fence method 5 outliers and for Outer fence method 3 outliers are formed. Tanagra

and other Data Mining tools are now emphasing on Outliers detection. But depend upon Dataset the outliers are vary from one application to other. Outliers are not only permitted to architectural level. During policy making also the outliers are formed internally or externally or locally or Globally.

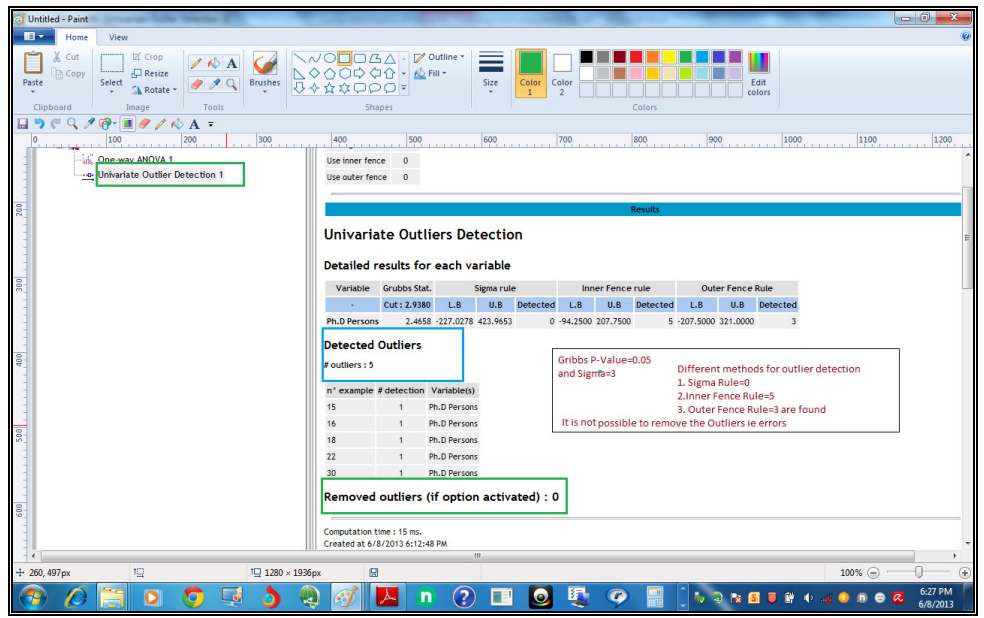

Figure 3.2c: Outlier detection

(Dendogram) Hierarchical Clustering of 6 attributes and 32 instances are available for Australian University Research Clusters. Single link or nearest neighbor algorithm is used for distance between clusters. 
International Journal of Artificial Intelligence \& Applications (IJAIA), Vol. 4, No. 4, July 2013

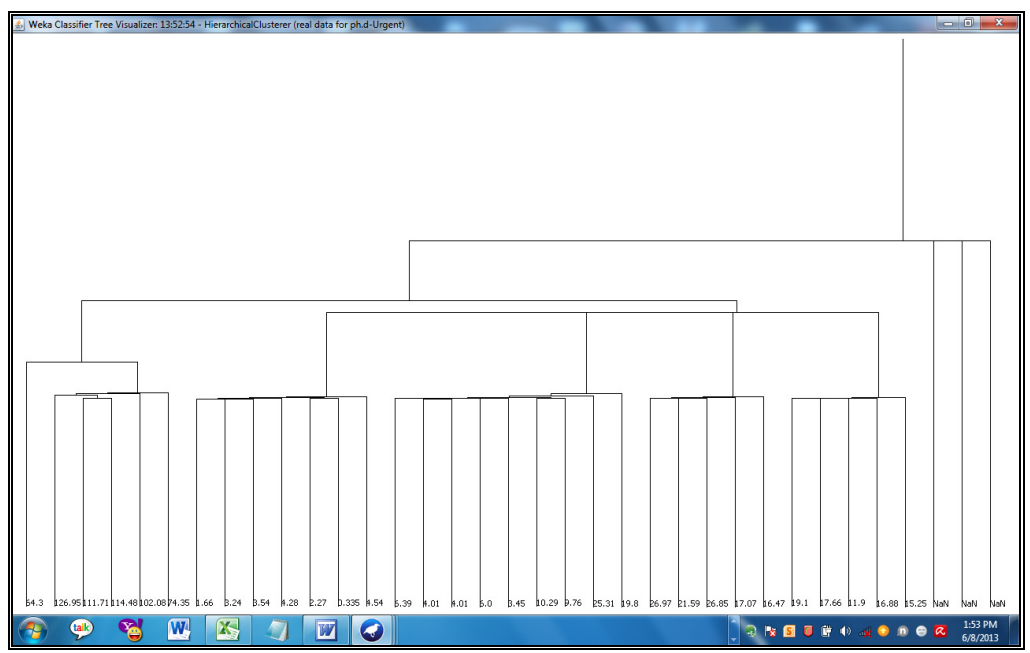

Figure 3.2d: (Dendogram) Hierarchical(Weka).

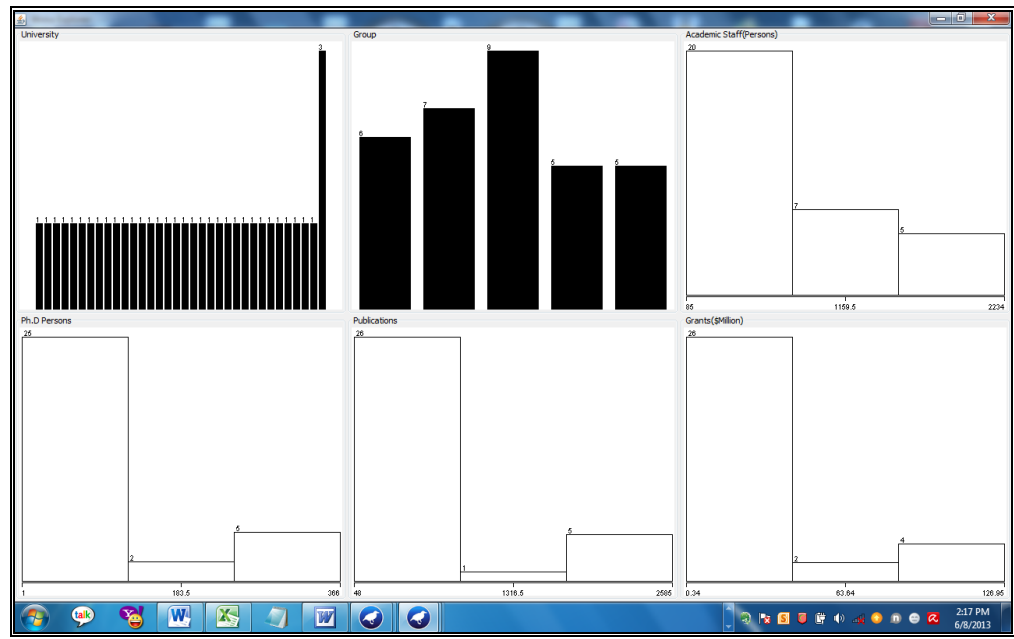

Figure 3.2e: Visualization for all 6 attributes.

\subsection{Continent level Clustering}

Heidelberg University and Tohoku University offer a joint doctoral program and initiated by Cluster Professor Harald Fuess. The new program me will enable students to receive a double degree from Heidelberg University and Tohoku University, Japan.The programme comes with a scholarship and includes a one-year stay at the Global Centre of Excellence "Gender Equality and Multicultural Conviviality in the Age of Globalization" in Sendai, Japan [3].

Heidelberg University, Germany. Consists of "Cluster-Excellence for Asia-Europe in global context. In this Bi-cluster there are totally 9 sub clusters are available. The main areas of implementation are Strategic planning, Academic, Finance, Admin and Research. Optional is available only for Technical clusters. 
International Journal of Artificial Intelligence \& Applications (IJAIA), Vol. 4, No. 4, July 2013

Middle East and North Africa Research cluster consists of mainly BI-Cluster. They are MENA 412 AND MENA 410 and/or MENA 411.Along with Middle East based languages different types of optional subjects are also available. One cluster is implemented for Languages and another cluster is implemented for optional subjects [10]. Arabic, Turkish, Persian, Hebrew, or Tamazight languages are available along with Anthropology, Art History, Comparative Literary Studies, History, Political Science, Religion, Radio/Television/Video/Film technologies. All dynamic clusters are treated as sub clusters and exceptional cases.

The York University, United Kingdom, Department of History has Research clusters for History subject. The area of clusters formation is Europe-Asia area which deals about the impact of empires in Asia and of Asian cultures on Europe studies, and to debates about the causes and consequences of globalization [11].Bi-Cluster implementation includes research on archival, textual and oral sources in West European and Asian languages, including Bengali, Bhojpuri, Chinese (modern and classical), Hindi, Japanese (modern and classical), Konkani, Marathi, Persian, Portuguese, Sinhalese, and Tamil. The official language of India is Hindi [26].So one cluster is useful for archival purpose and other for language research as Euro centric [11].

Case studies of Japan, German, and France Bio-Clusters are under Institute of Economic Research Hitotsubashi University, Tokyo, Japan have official publication paper on Bi-Clusters of Asia-Europe. The sample space countries are Japan, German and France. They have totally 5 technical (Bio-Technology) clusters. Three clusters from Japan, one from Germany and one from France [51],pp1.Especilally for Technical clusters, networking between industries and Universities are important for innovation(Mayer-Kramer and Schmoch 1998).Basically Local Productive Systems are the main core of French cluster policy [52],pp 3.France clusters are more flexible than Japan and Germany cluster policies[51],p6.All clusters are sponsored by respective Governments [51],pp 26.In Japan except "City Area" cluster all clusters are implemented as top-down approach. In Germany and France all clusters are applied bottom-up approach [51], pp 4-6.

\section{PROPOSED FRAMEWORK FOR PROPOSED SYSTEM.}

\subsection{Node level}

To develop the University Clustering System for country wise it is necessary to estimate the size of the data as per UGC 12th Five Year Plan. The size of the data must be consistent and unique. Let us assume " $n$ " Universities are in India. On the basis of financial status, reputation of university, direction, category, nature, geographical conditions, policy, gender, Social needs etc. estimate initial clusters. Here proposed algorithm for cluster initiation on the basis of accreditation.

Algorithm-1. Create IN, PRE, AND POST Order tree with assumed value. Input: - maximum ' $n$ ' Universities are available. Consider ' $k$ ' Universities are fit for clustering. $\quad(n-k)$ are unfit for clustering and only ' $m$ ' are assumed as perfectly holds good, generally $m<k$ (Practically). Process:-

Step1:- Initiate root value on the basis of accditation.Allot children to root as per rank

Of Universities and form a tree until zero or null or minimum 
International Journal of Artificial Intelligence \& Applications (IJAIA), Vol. 4, No. 4, July 2013

accreditation takes place.

Step 2:- Create IN, PRE, And POST order trees

Step 3:- Evaluate the path as per standard algorithms

Output: - IN, PRE, And POST order trees are available with paths.

Algorithm-2. Estimation of Network Cost.

Input: - IN, PRE, And POST Order trees are available.

Process: - Use any spanning tree algorithm and find minimum cost for available tree.

Output: - Minimum cost of path can be estimated which is termed as Network cost.

Algorithm:-3 Apply Clustering Algorithm on nodes obtained in Algorithm Input: - $m$ nodes obtained from Algorithm-2

Process:- Apply k-means algorithm or any Unsupervised algorithm for clustering

Output:- Number of clusters are available $<m$ (Defined in Algorithm)

\subsection{Database level}

For prototype models only specifications are allowed but not table with Normalization. Since this is proposed model as per strategic level.At tactical or operational level all tables are available with normalization forms

\subsubsection{Types of attributes in available Database ( For specification's)}

a. Single value

b. Binary values (0 OR 1) OR (Yes OR No )

c. Multiple values

\subsubsection{Cluster level Specifications}

Id,Cluster_Id,Cluster_Name,No_Of_Clusters,Cluster_type,Sponsor,Time_Period,Budjet_estim ation,Budjet_alloted,Process(top_down,bottom_up),location_of_clusters,parent_cluster_id,loca 1_clusterORglobal_cluster

\subsubsection{University level Specifications}

SNo,University_Name,University_Type,University_Rank,University_Location,Groups, ELarning,Recruitment,Reservation_Policy,result\%,AICTE_Recg,PG_Core_Subjects,PG_Applied _Sciences,Professors,Hostels,Library,Library_Rank,Train_Facility,University_Hospital,videoconf erence,Server_Location,Servers_Rank,No_Of_Servers,Tech_Support_Rank,ETrained_Staff,MOU _Colleges,MOU_Universities,Web_Ranking,Multiple_OS_Available,Multiple_OS_Server_Availa ble,Separate_Team,Separate_Team_Location,ETools,E-Fund, E-material, E-staff, E-methods, Education-Satellite, E- standards\%, Audit,ELevels,Online_Courses,Wi-Fi,WiFi_Units,Commitee_Experts, Commitee_Experts_Location, University_ Grade, University_ Direction, Node_ Type,Air_port_facility, Foreign_Languages_Dept, Female Students\%,Funds_For_Research, Free_Laptop_facility, Free_USB_Facility, University_ Bus, Interdiscipline_Research, Faculty_Refresh_Course, Faculty_Refresh_Course_Sposnsor, Core_ Research 


\subsubsection{Policy based Specifications}

Unlike cluster and Universities specifications, Policy specifications are more dynamic in nature. Since policies are depend on respective Ministries decisions and give Database form surely create more ambiguous in nature. Local based procedures are more important for formulate the policies [52], p1. Due to Local based procedures more local clusters are formed [52], p3. Due to its local clusters the process may be top-down or bottom-up approach [51], p4.So specifications are applicable for Tactical level and Operational level but not strategic level. Even though specifications are available they are highly unstructured. Tactical and Operational specifications are semi and full structured .Generally any Governance in the world prefers Management Information Systems for its policy implementation.

\section{Implementation of University clustering With reference to FrameWork}

Distance matrix consists of 30*30 matrix(900 entities).30 locations are randomly selected on the basis of SOUTH,NORTH,EAST,WEST AND NORTHEAST directions. All 30 locations are selected on the basis of alphabetical order for easy of use.

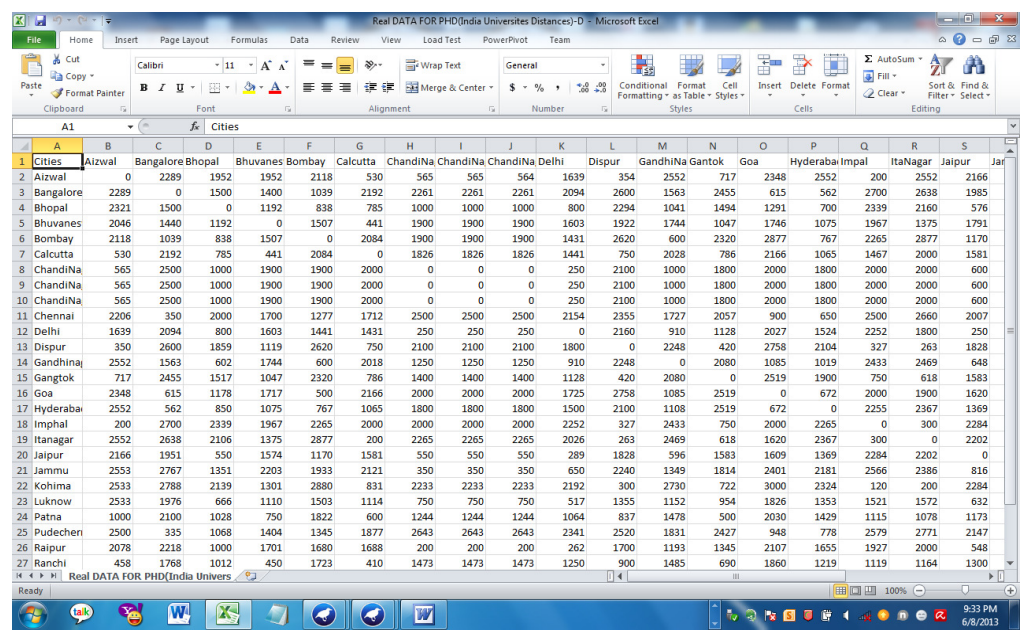

Figure 5a:. Sample Distance for 30 random selected locations

Weka-3.7 Visualization for University Location Sample .All 30 locations is considered. Distance between all 30 locations forms $30 * 30$ matrix(900 elements) 
International Journal of Artificial Intelligence \& Applications (IJAIA), Vol. 4, No. 4, July 2013

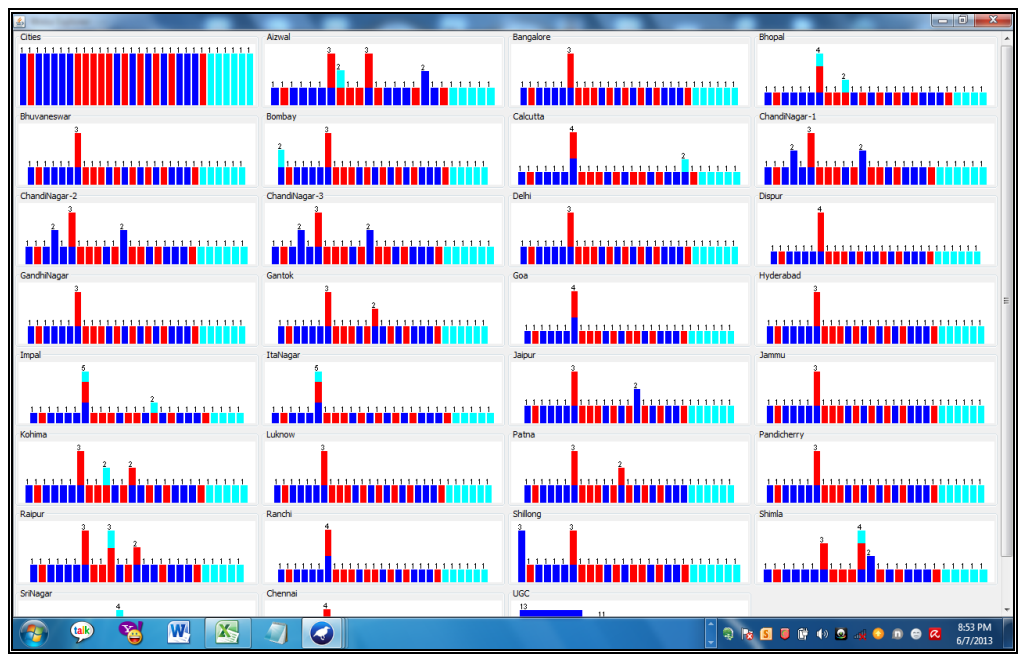

Figure 5b. Weka-3.7 Visualization for University Location

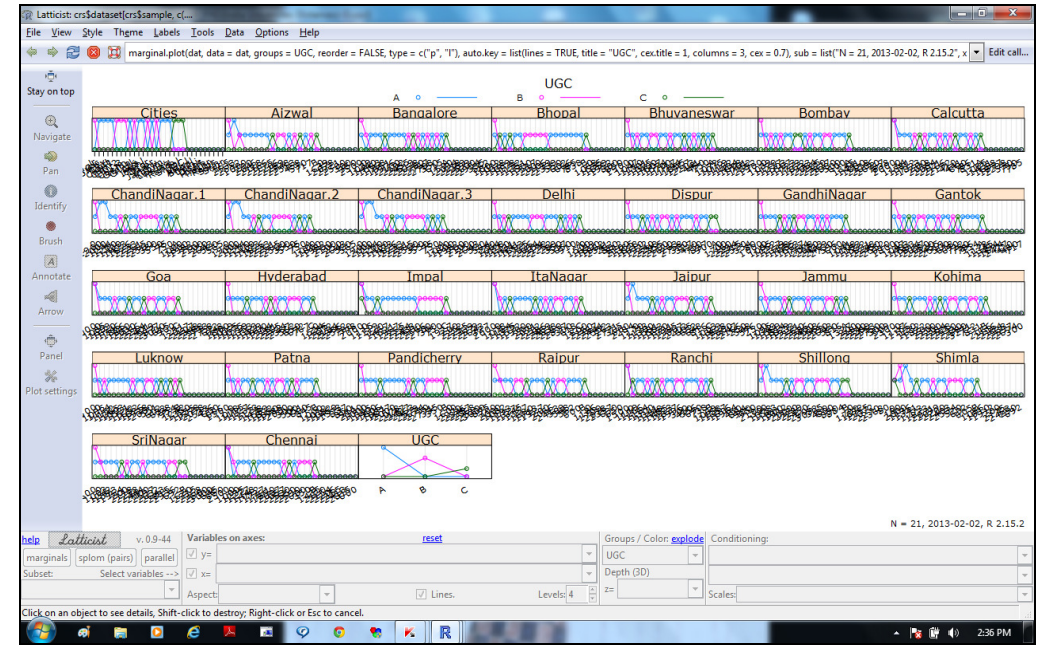

Figure 5c: Linear Projection with respect To Chennai(Red line)

10 Association Rules are found with this Sample. Minimum support 0.15 , Confidence $=0.9$ for 30 nodes of different locations sample. Zero examples are left. The number of rules are generated is completely depend upon minimum support and confidence level. 
International Journal of Artificial Intelligence \& Applications (IJAIA), Vol. 4, No. 4, July 2013

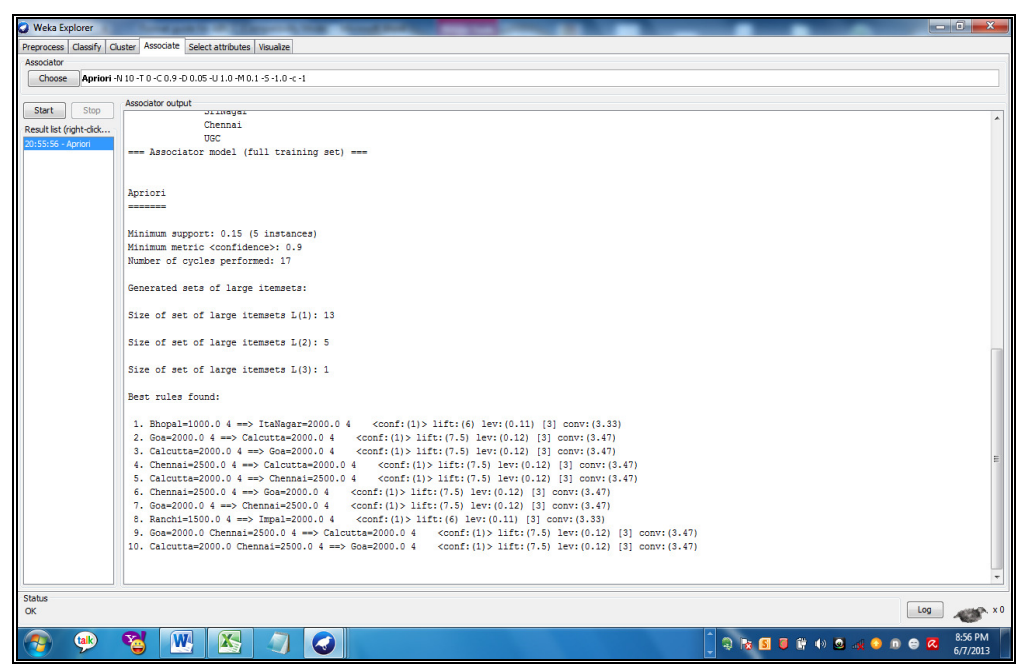

Figure 5d: Association Rules

Supervised method(Navie Bayes) method is applied for given sample with 30 entities with Confusion matrix and Mean absolute error $=0.0222$. Confusion matrix gives the quality of Sample.

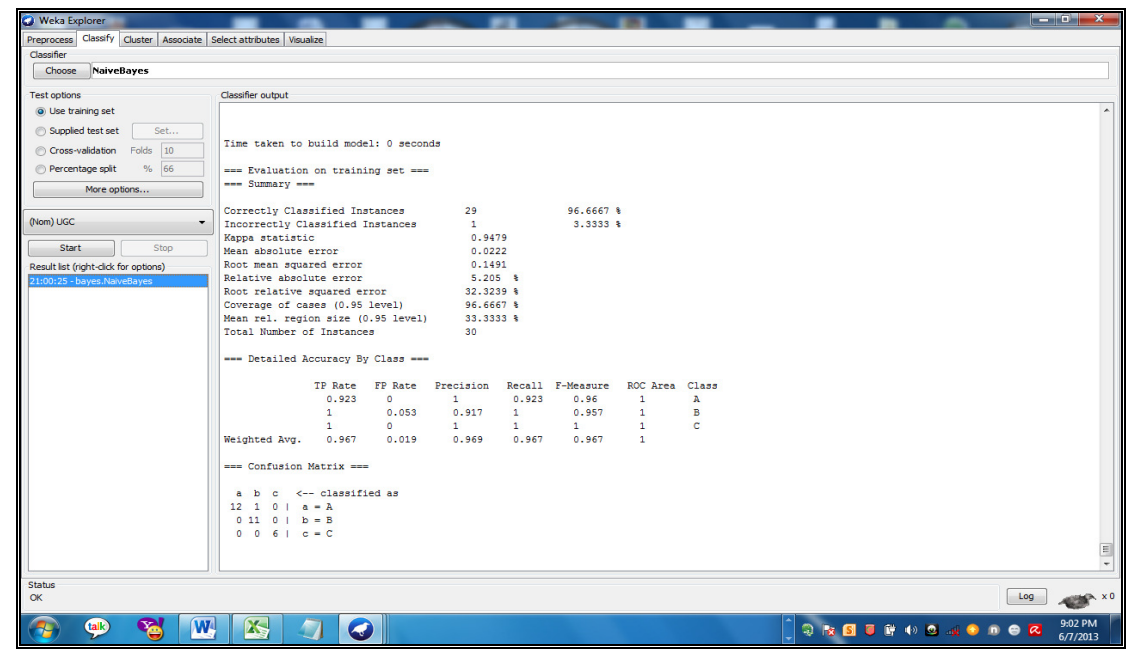

Figure 5e: NavieBayes method with Confusion matrix(Weka tool)

Hierarchical Cluster with Tree form with 30 nodes and tim taken to built the tree $=0.01$ seconds.There are 300 entities are available(30*30).Hierarchical clusters are implemented with TANAGRA tool. Total computational time is $16 \mathrm{~ms}$. Cluster1 has 11 , cluster 2 has 6 and cluster3 has 13 nodes. Total 30 nodes are available in Random Sampling. 
International Journal of Artificial Intelligence \& Applications (IJAIA), Vol. 4, No. 4, July 2013

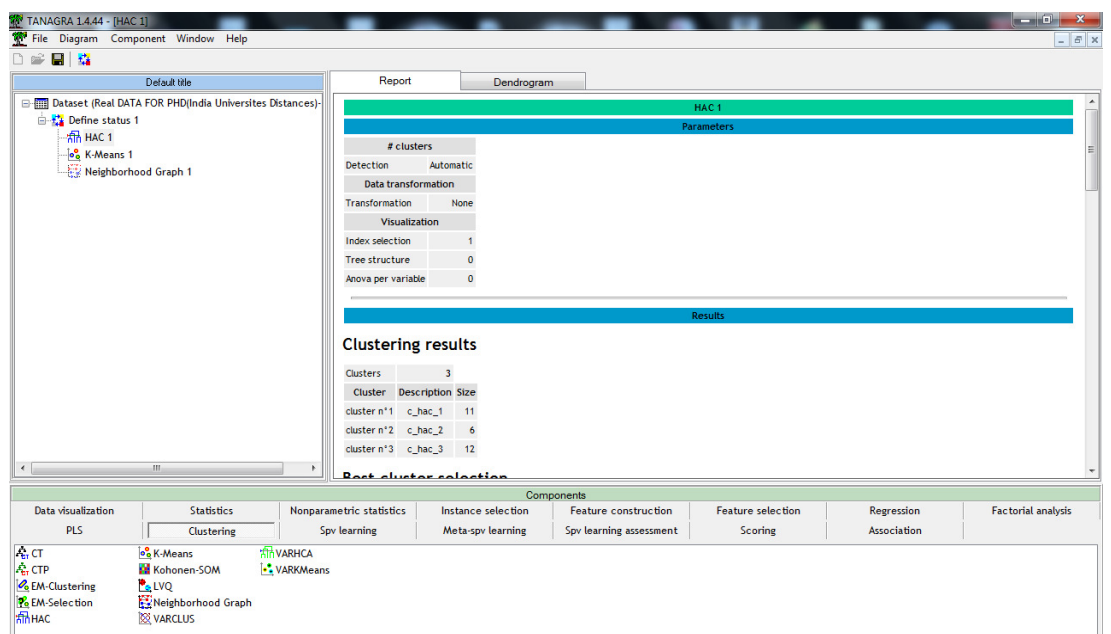

\section{(A) W W}

Figure 5ee: 3 Clusters are formed for 30 nodes(Tanagra tool)

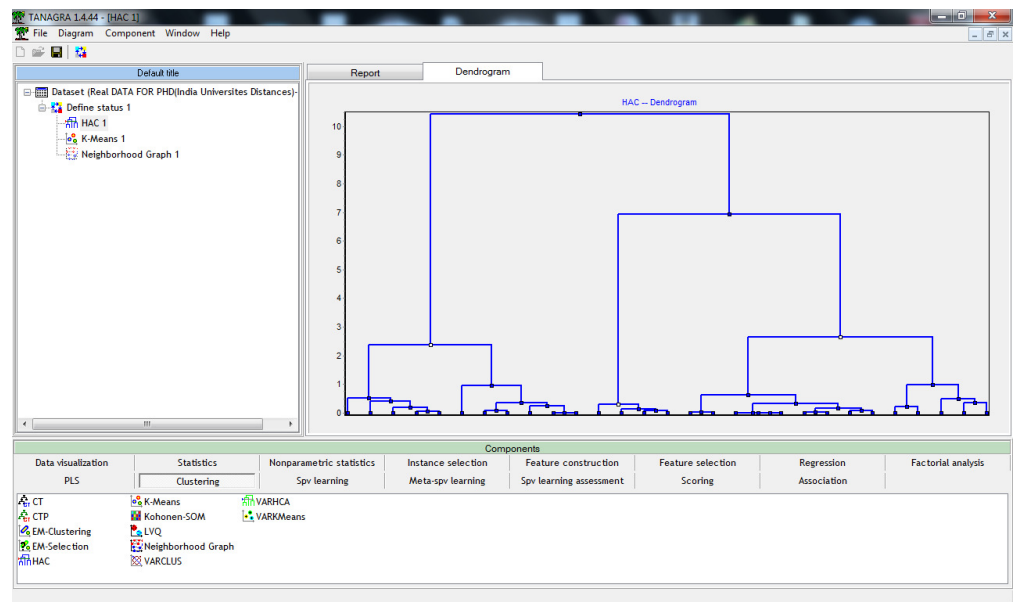

(2) कु W

Figure 5f: .Hierarchical Cluster with Dendogram 30 nodes with height=10(Tanagra tool)

Visualization is available here in the form of all nodes with respect to $\mathrm{x}$ and $\mathrm{y}$ axis. All nodes are available in the form of Grid and each time we can select one item for enlarge the image. In Weka for clarity of image we can adjust the jitter values, in such a way that the image should be visible as per data. 
International Journal of Artificial Intelligence \& Applications (IJAIA), Vol. 4, No. 4, July 2013

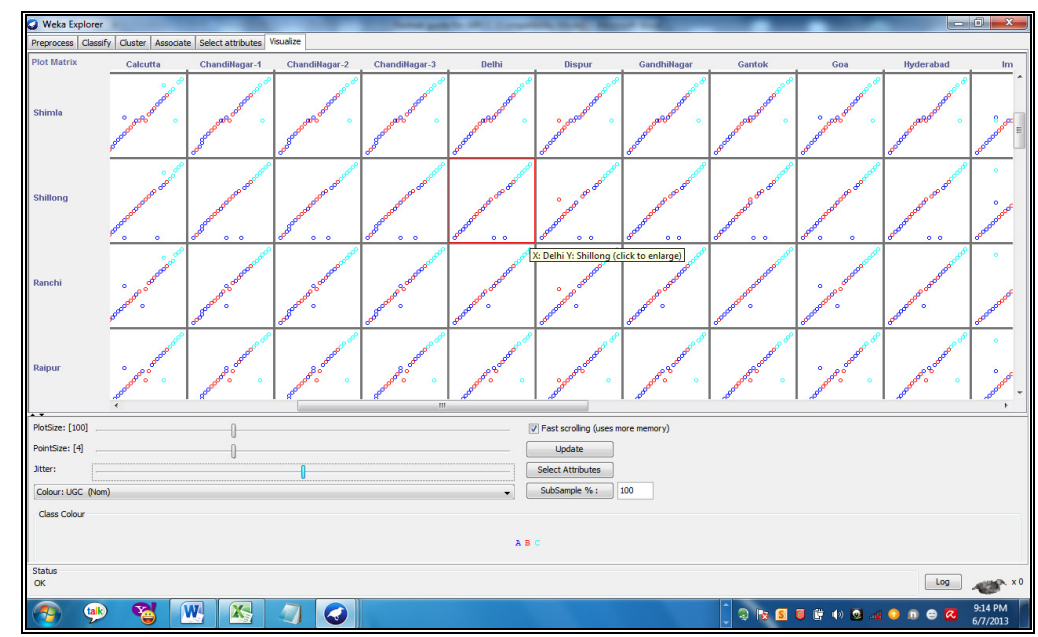

Figure 5g: Visualization of all locations with 2D form(X And Y Axis)

Load the Database into Weka tool for all types of Universities as per UGC list with minimum=1, maximum=31, Mean=16 and standard deviation=9.1.Standard form of Dataset is .arff .But both .arff and .csv files are used as Dataset. All types of Universities are loaded into Weka tool for Modelling.

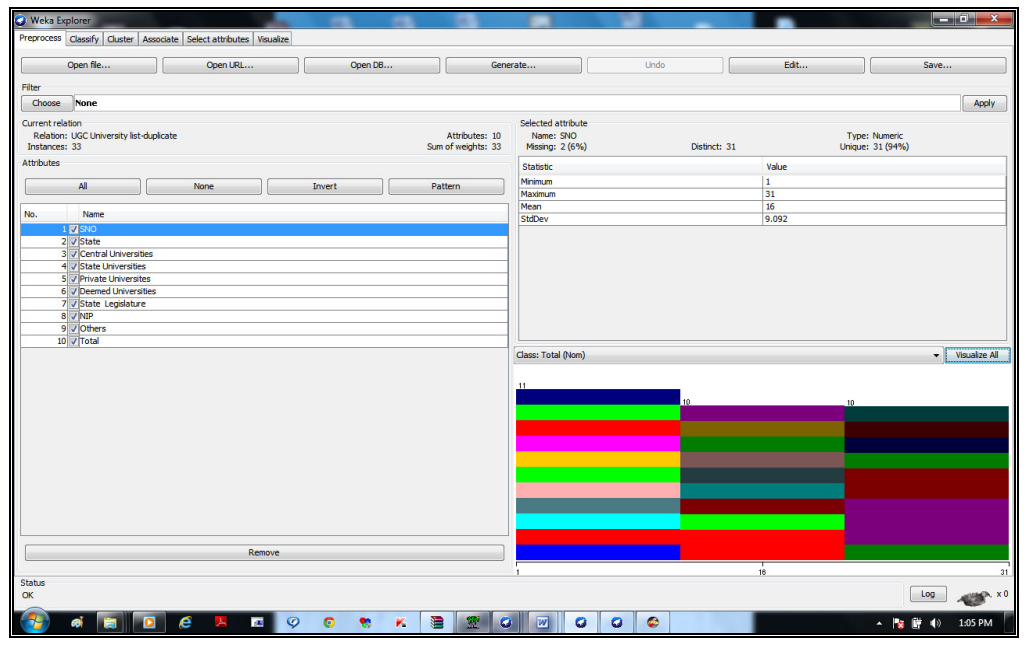

Figure 5h: Weka tool for all types of Universities

Visualization is one type of GUI technology which analysis the things on the basis of 2Dor 3D.Actually Visualization is not a part of Data Mining technique. But when more attributes are available in Dataset then only first $m$ items are sequentially selected. Scaling methods and GUI methods are different from one tool to other. Generally Visualization is useful for extract the information from different models into GUI [55], pp-1. 


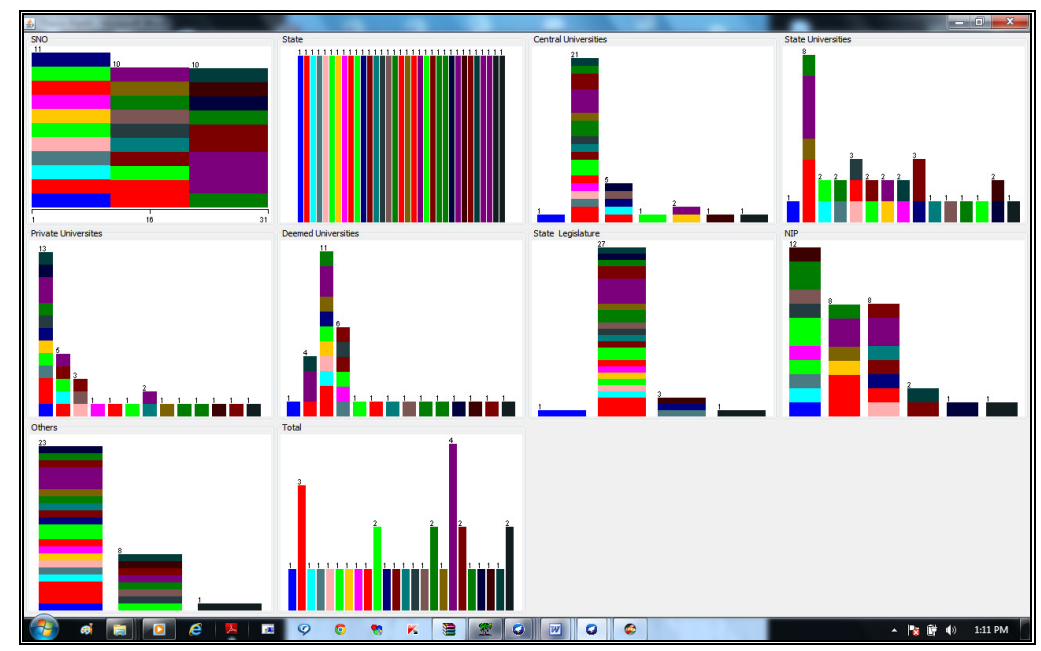

Figure 5i:: Visualized with Weka 3.7 Data Mining Tool.

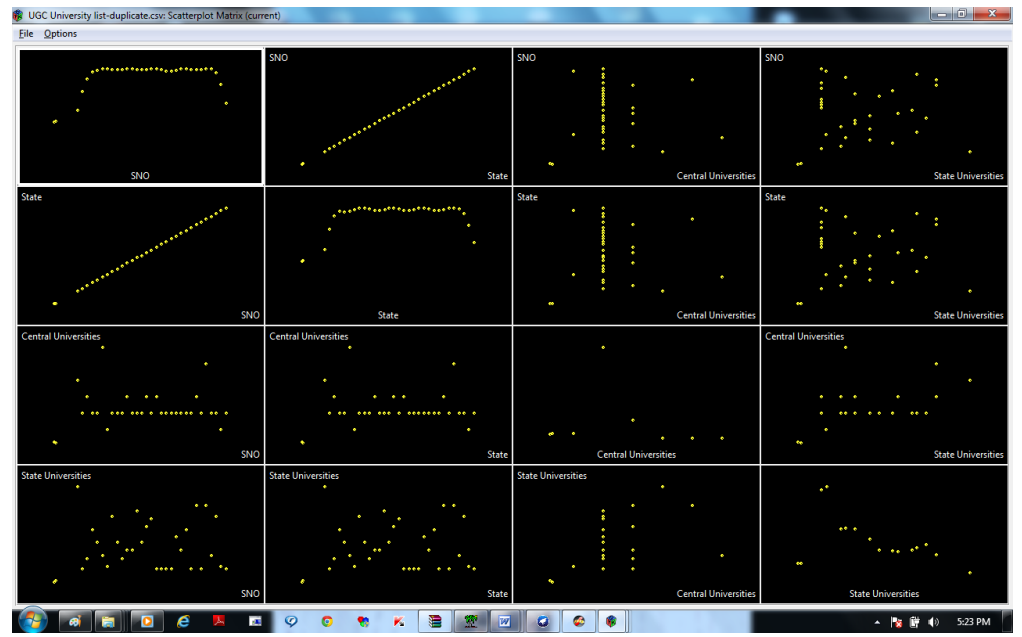

Figure 5j: Visualization of UGC list,Indian Universities (with Ggobi software).

Unsupervised Methods are useful to construct the Clusters for Universities which are defined as On the basis of states. Hierarchical clustering method is useful when we have a distance matrix. Here we applied Hierarchical clustering with Wards linkage. Dendogram also available. Height is 0.73.This height is different from one distance method to other.

In this we implemented Hierarchical Clustering Wards linkage with Euclidian Distance. There are different tools are available and dedicated tools are also available. Out of available generally for Research and studies some special software are available. They are TANAGRA, R,WEKA, and ORANGE etc. Along with Microsoft SQL Server we can get Data Mining Service Analysis. Hierarchical clustering has lot of advantages when compare to other clustering methods. Orange and R consider mixed type of Inputs. ORANGE tools have lot of Visualization facilities Due to prototype Model nature it is not possible to estimate total number of records in Data base. But some attributes of binary and category nature. So we can easily apply supervised methods as per 
context. If we apply different linkages for Hierarchical Clustering the height of resultant cluster has different value. Generally Dataset may be in the form of .xls, .arff, .txt,. csv etc.

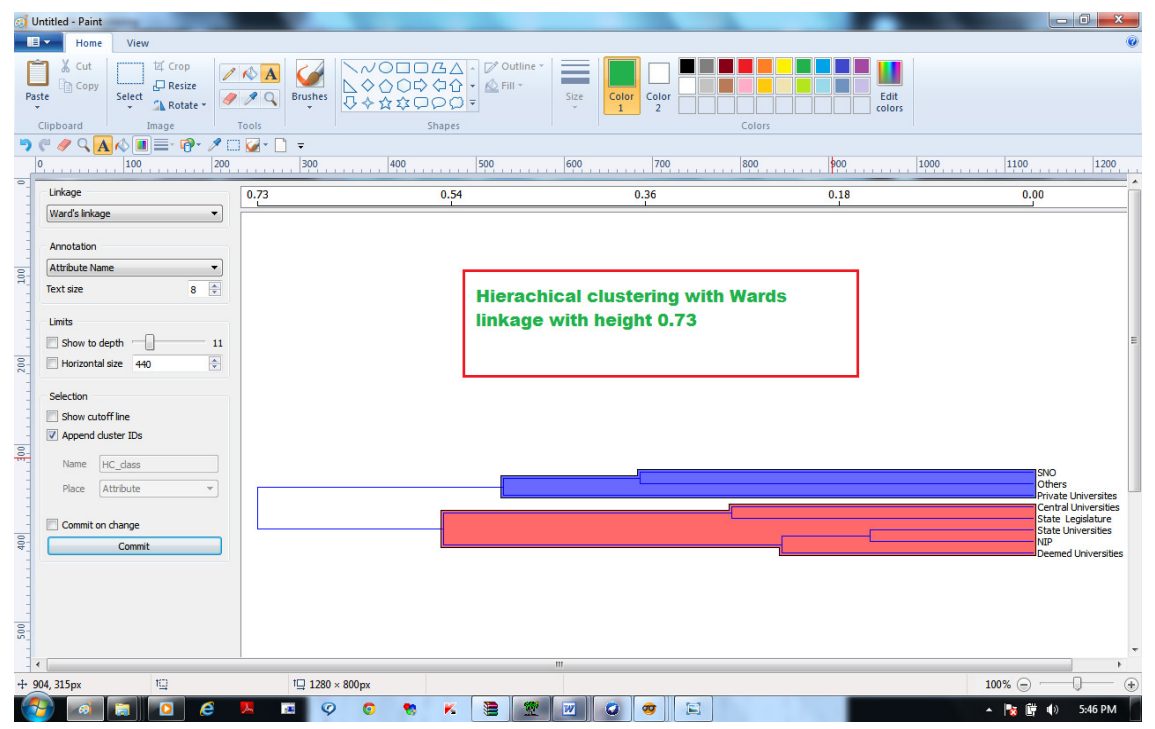

Figure 5k: Hierarchical clustering Wards linkage.

University Database list is loaded into tool Gephi 0.82 version for Network modelling.In this model we can get direct and Undirect graph with Visualizations.Details of Network Modelling for Proposed system comes under Technical Cluster Analysis.For prototype model Technical specifications are optional. University Database list is loaded into tool Gephi 0.82 version for Network modeling for Directed Graph. Generally Graph theory is most suitable for prototype model networks. Non Linear Data structures are also implement for obtained or given networks in the form of nodes.

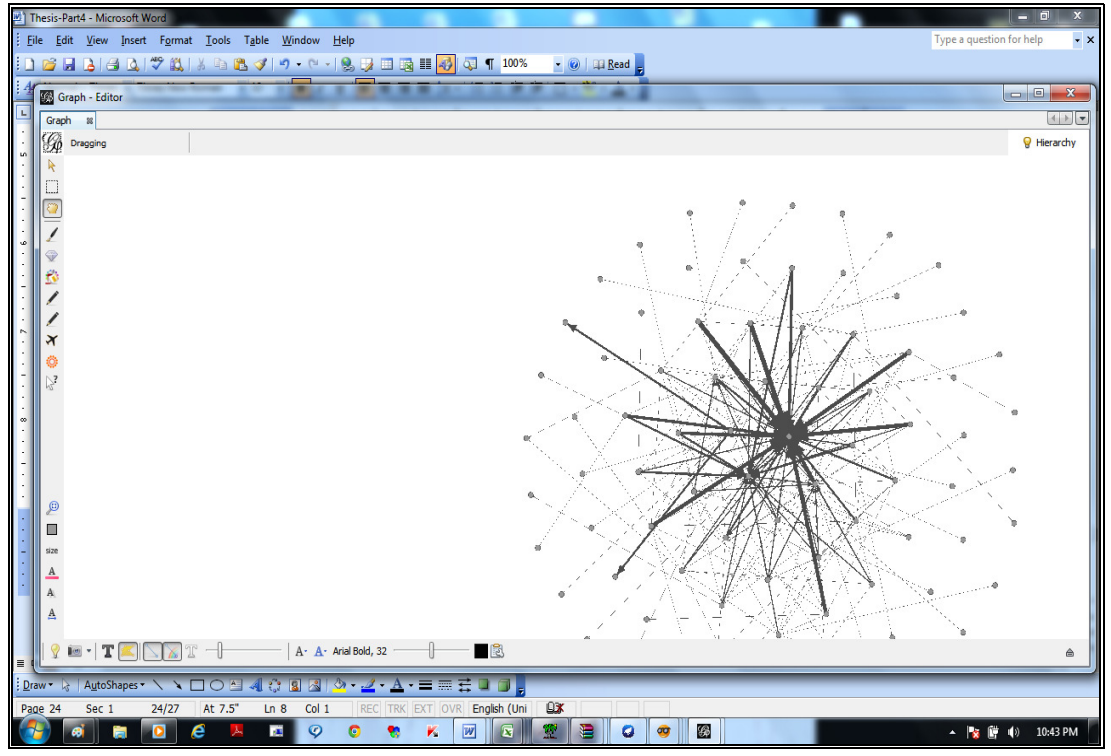

Figure 5l:. Directed Graph generated with 84 nodes, 198 edges 
International Journal of Artificial Intelligence \& Applications (IJAIA), Vol. 4, No. 4, July 2013

\section{CONCLUSION}

When compare to developed countries, India has old models and trail and error methods. Depend upon UGC 12TH FYP it is very difficult to estimate exact database and number of clusters. Since this is Strategic plan for next five years (2012-16).Due to different conditions in India the uniform policy should not available [26]. So for India lot of Local clusters are necessary. So more studies are necessary on Japan, German and France CASE STUDIES which may be maximum suitable to India's environment. Prototype model should be implemented for avoid the ambiguity in different cluster policies. Deep research is necessary on creation of Local Clusters and scope of clusters.

\section{ACKNOWLEDGEMENTS}

The authors would like to thanks for all teachers from school level to Research level.

\section{REFERENCES}

[1] http://ibr.hi.is/sites/ibr.hi.is/files/Location_CCompetition_and_Economic_Development_Local_ Clusters_in_a_Global_Economy.pdf

[2] http://en.wikipedia.org/wiki/German_Universities_Excellence_Initiative\#Winners: _Clusters_of_Excellence

[3] http://www.asia-europe.uni-heidelberg.de/en/news-events/news/detail/m/joint-doctoral- $\quad$ programwith-tokoku. html

[4] http://www.wpunj.edu/registrar/registration/cluster-programs.dot

[5] http://www.fas.nus.edu.sg/research/centres.html

[6] http://www.fas.nus.edu.sg/research/clusterupdate2013sem1.pdf

[7] http://www.eng.nus.edu.sg/eitu/pc.html

[8] http://utown.nus.edu.sg/about-university-town/education-resource-centre/study- clusters/

[9] http://www.ari.nus.edu.sg/article_view.asp?id=921(Science and IT)

[10] http://www.tgs.northwestern.edu/academics/academic-programs/clustercertificate/humanities/mena/cluster-requirements/index.html

[11] http://www.york.ac.uk/history/research/researchclusters/amea/Asia-MiddleEast

[12] http://socialsciences.exeter.ac.uk/iais/research/clusters/Arab-Islamic-studies

[13] http://www.thunderbird.edu/wwwfiles/sites/globe/pdf/jwb_arab_cluster.pdf

[14] http://search.calstate.edu/search?site=sfsu_all\&output=xml_no_dtd\&client=sfsuedu\&proxystylesheet $=$ sfsu-edu\&q=clusters

[15] http://www.fujitsu.com/hr/Images/120727_CS_Fujitsu_SQUH_en.pdf

[16] http://www.diacedu.ae/component/search/?searchword=CLUSTERS\&ordering=\&searchphrase=all DUBAI-INTERNATIONAL ACADEMY

[17] http://www.kaust.edu.sa/search/search.html?cx=003599135184284100168\%3Aoh_nsn$12 \mathrm{p} 4 \& \mathrm{cof}=\mathrm{FORID} \% 3 \mathrm{~A} 11 \% 3 \mathrm{BNB} \% 3 \mathrm{~A} 1 \& \mathrm{ie}=\mathrm{UTF}-8 \& \mathrm{q}=\mathrm{clusters} \& \mathrm{sa}=$ Search

[18] http://sicd.se/wp-content/uploads/2012/06/Research-Report-Seaweed-Salt-2011.pdf

[19] http://www.massey.ac.nz/massey/about-massey/subsidiaries-commercial-ventures/centre-foreducational-development/professional-learning/clusters/clusters-networks_home.cfm

[20] http://www.eresearch.org.nz/nz-eresearch-symposium-2010

[21] http://staff.business.auckland.ac.nz/DesktopModules/StaffProfiles/Publications/8631.pdf

[22] http://www.ugc.ac.in/oldpdf/commissiondecision/425.pdf PAGE-17

[23] http://www.ugc.ac.in/pdfnews/9211228_Centurian.pdf PAGE-12 10 CLUSTERS

[24] www.ugc.ac.in/oldpdf/xiplanpdf/womenstudies.pdf

[25] www.ugc.ac.in/ugcpdf/740315_12FYP.pdf Innovative clusters 
International Journal of Artificial Intelligence \& Applications (IJAIA), Vol. 4, No. 4, July 2013

[26] http://en.wikipedia.org/wiki/India

[27] http://socialsciences.exeter.ac.uk/iais/research/clusters

[28] http://www.thunderbird.edu/wwwfiles/sites/globe/pdf/jwb_arab_cluster.pdf

[29] http://www.diacedu.ae/component/search/?searchword=clusters\&ordering=\&searchphrase=all

[30] http://www.dal.ca/search.html?stype=main\&q=clusters

[31] http://informatics.medicine.dal.ca/PastHISeminars.htm

[32] http://www.dal.ca/content/dam/dalhousie/pdf/dept/senior-administration/ss_report_11.pdf

[33] http://www.massey.ac.nz/massey/search.cfm?cx = 007028990505551826392\%3Amqdofac7ule\&cof $=$ FORID\%3A9\&ie $=$ UTF- $8 \& \mathrm{q}=$ clusters \&searchtype $=$ all

[34] http://www.massey.ac.nz/massey/learning/colleges/college-creativearts/people/research/matter/initiatives/clusters-and-loci_home.cfm

[35] https://www.massey.ac.nz/massey/research/research-support/research-support_home.cfm

[36] http://www.eresearch.org.nz/soer-projects/selection-tools-for-genomics-researchers

[37] http://www.eresearch.org.nz/search/node/clusters

[38] http://www.eresearch.org.nz/content/r-grid

[39] http://www.eresearch.org.nz/content/mono-brings-net-linux-hpc39]

[40] http://staff.business.auckland.ac.nz/DesktopModules/StaffProfiles/Publications/8631.pdf

[41] http://presiuniv.ac.in/web/introduction.php

[42] http://presiuniv.ac.in/web/research_physics.php

[43] http://cic.du.ac.in/cic/innovation.html

[44] http://attractproject.org/sites/default/files/document/Attract\%20Project\%20-\%20Full\%20Report\%20$\% 202012 . p d f$

[45] http://www.brightonfuse.com/wp-content/uploads/2012/02/Brighton-fuse-universities-and-cditclusters.pdf

[46] http://www.arc.gov.au/pdf/P_UTASPCE_11Jul09.pdf

[47] http://search.uiowa.edu/search?entqr=0\&ud=1\&sort=date\%3AD\%3AL\%3Ad1\&output $=x m l \_n o \_d t d \& o e=U T F-8 \& i e=U T F-c l i e n t=d e f a u l t$ frontend \&proxystylesheet=our_frontend $\&$ site $=$ default_collection $\& q=$ clusters

[48] http://provost.uiowa.edu/clusters/docs/ClusterHireInitiativeGuidelines.pdf

[49] http://www.provost.uiowa.edu/clusters/docs/ClusterWhitePaper.pdf

[50] http://www.value-leadership.com/download/vlg_ranga_emerging_research.pdf

[51] http://cei.ier.hit-u.ac.jp/English/database/documents/wp2011-7.pdf

[52] http://econ.sciences-po.fr/sites/default/files/file/tmayer/spl_pub.pdf

[53] http://ro.uow.edu.au/commwkpapers/125

[54] Introduction to Data Mining With Case Studies : Second Edition : "Dr. G.K.Guptha", Professor of ComputerScience,Manosh University,Austrialia.

[55] http://www.kurims.kyoto-u.ac.jp/EMIS/journals/NSJOM/Papers/37_2/NSJOM_37_2_161_180.pdf

\section{AUTHOR PROFILES:}

Mr.Srinatha Karur is Research scholar and has both academic and technical profile. He completed M.CA from Gulbarga University campus on 1997- May, M.Tech (IT) from Punjabi University, GGSIIT, 2002-04, Patiala, India, and M.Phil. from Global University, Kohima, India, 2009 December.

Prof.M.V.Raman Murthy is senior professor and Director for Department of Computer Science, Osmaina University, Hyderabad, India. He is author of core programming languages and international Publications on different applications. His profile shows his complete grip on Academic,Administration and Technical fields.

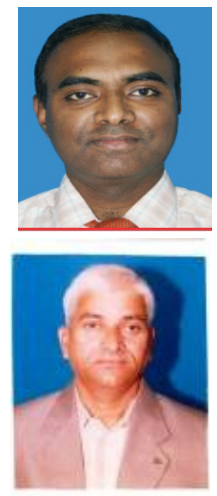

